structed as to present ready communication with each other, and afford facilities, by distribution of speaking-tubes and openness of access, or otherwise, for a due and prompt superintendence.

Such an institution, with its rural and village attributes, and, in a wide degree, with its accordant occupations, rivalries, interests, and amusements, we are convinced, would be no impracticable project; and the primary cost of its complete establishment, with the purchase of the land, and the addition of every desirable appurtenance, adapted to a population of three hundred patients, with a full complement of officials, would, at a rough estimate, not exceed $150 l$. for each patient, so that a judicious management might render it safely remunerative, and at an even unusually moderate scale of charges.* An establishment, however, for half this number of patients would, if not in an economic, at least in a scientific and curative point of view, be infinitely preferable ; for any attempt to individualize cases with the slightest pretension to adequacy, among the masses now usually congregated under a scanty medical staff in our leading asylums, is but a ridiculous pretence, the futility of which forms one of the most prominent defects in their constitution. It is evident that, after the completion of the buildings of our cure-village, the free-stone for which we should hope to be supplied within the limits of the property, much of the subsequent labour in the original laying out of the precincts, walks, gardens, \&c., might be advantageously accomplished by the patients, under a qualified guidance, and this independent of the succession of appropriate and genial occupations to be secured to them afterwards. Will any of our three Lunacy Boards thank us for our suggestion?

\title{
Review II.
}

1. Elements of Pathological Anatomy. By Samuer D. Gross, M.D., Professor of Surgery in the Jefferson Medical College of Philadelphia, and formerly Professor of Pathological Anatomy in the Medical Department of the Cincinnati College. Third Edition. Illustrated by Three Hundred and Forty-two Engravings on Wood. -Philadelphia, 1857. pp. 771.

2. Human Histology in its Relations to Descriptive Anatomy, Physiology, and Pathology. By E. R. Peaslee, A.M., M.D., Professor of Physiology and Pathology in the New York Medical College; of Anatomy in Dartmouth College ; and of Surgery in the Medical School of Maine. With Four Hundred and Thirty-four Illustrations on Wood.-Philadelphia, 1857. pp. 616.

3. Die Kunstgerechte Entfernung der Eingeweide des Menschlichen Körpers; Ein Leitfaden für Wissenschaftliche Leichenöffnungn. Von G. Valentin, Prof. in Bern.-Frankfurt-am-Maine, $18 \tilde{7}$. pp. 44.

On the Scientific Mode of Removing the Viscera in Performing Autopsies. By Professor Valentin.

* At the extensive asylum of Slesvig, a new division for the females has been built from savings produced chiefly by the well-managed agricultural labour of the patients.-Dahl, Norsk Magazin for Lagevidenskaben, 1857, p. 391. 
Is taking up a treatise on Pathological Anatomy, we feel ourselves in a special manner confronted by the science of our calling. We come to learn what disease does, we seek to know what disease is. It is no more a matter of detecting and weighing signs, of finding indications to direct our therapeutic efforts, of administering remedies whose working we dimly or not at all comprehend. The "befund" of the necropsy in the majority of instances is the dictum from which there is no appeal, the final proof to which the accomplished diagnostician confidently refers for a fulfilment of his predictions, and without which our French brethren of an earlier period used (if we may trust on dit) scarcely to consider a case complete. But, we need not say it, the knowledge of the material changes wrought by disease is not the only aim of pathological anatomy; beyond this, indeed, morbid anatomy does not go, but the complete science has a far wider scope. Who can look at a pleura full of fluid, a contracted or tattered valve, a liver far gone in fibroid change, or a cancerous tumour, and feel no inward questionings as to how these things came to be? Deep planted in the human breast is the tendency to inquire into causes. So wrote Virgil,

" Felix qui potuit rerum cognoscere causas,

Atque metus omnes et inexorabile fatum

Subjecit pedibus ;"

and so in our own day one of the largest minds states it as his deliberate conviction, that "it appears to be required, both by the analogy of the most successful efforts of science in past times, and by the irrepressible speculative powers of the human mind, that we should attempt to discover both the laws of phenomena and their causes. In every department of science, when prosecuted far enough, these two great stages of investigation must succeed each other." Thus, then, our morbid anatomy of necessity leads us on to pathology, to inquire into the "story" of the causation of the material changes which the eye contemplates. Let it be said at once that here we must come short, must feel the exceeding imperfection of our knowledge. Morbid anatomy is well nigh as complete as its healthy counterpart; the diseased body, like the normal, has been minutely scanned and explored and described. But in physiology we have but dim and imperfect ideas of the various powers that move the vital machinery; and in pathology we have still less knowledge of these changed and perverted motors, or of the agencies that have so affected them. Painfully does the medical philosopher feel this, especially as his mental thirst is intensified by the sympathy he must have for human suffering, and the call ever sounding: to him to relieve it if possible. The mere morbid anatomist may elaborately detail all the "insatiable variety" of form and arrangement which cancerous growths display ; but the physician, whose heart and thoughts are with the living, craves with an impatient longing. for one gleam of light to indicate the essential substratum of all these morbid erections, one ray to show what rational means he may adopt to nullify the fatal influence. It almost seems to him a poor trifling to describe so curiously all the things that are non-essential, and to leave wholly untouched, even by an effort, the vital point.

The author whose work stands first on our list seems by no means 
to participate in these views. We quote a passage from the commencement of his volume, which expresses very plainly his abnegation of all deep inquiry, and prepares lis readers for the kind of information they are to find in the succeeding pages :

"Of the essence of disease," says Dr. Gross, "very little is known; indeed, nothing at all; nor can the utmost ingenuity hope to remove the veil which still envelopes the subject, until the physiology and pathology of the vascular and nervous systems shall be better understood. The proximate cause of morbid action, and the immediate cause of life in the healthy state, are as inscrutable to the human mind as the cause of gravitation, of attraction, and repulsion. All we can boast of is, that we know something of their effects; beyond this, it is extremely problematical whether we shall ever be able to penetrate. With this, indeed, every philosophical inquirer after truth should be contented, remembering that the secrets of Nature are not easily detected, and that to God alone belongs the knowledge of the intrinsic property of things."

We do rather marvel that one belonging to a so eminently "goahead" nation should have given the above as his deliberate opinion. Have no steps been taken, no great advances made, in the knowledge of the physiology and pathology of the nervous and vascular systems? Have Bell, and Marshall Hall, and Reid, and Bernard won no ground for us? Is the experience of the past such as to discourage hope for the future? Though we may never know the immediate cause of life, yet surely we may be permitted to discover that which perverts the normal course of health, and we may discern in what direction the perversion takes place. The cause of gravitation, very probably, we shall never be able to reach; we can only assign it to the great First Cause, and consider it as an ultimate property of matter. But could the physiologist produce for vital phenomena so comprehensive and sufficient a theory as the astronomer can for cosmical, what a gain for science it were! True it is the secrets of Nature are not easily detected; but what then? Are we to sit down and refuse the search, or are we to gird our loins for more earnest and intelligent toil? Had Kepler and Newton reasoned as Dr. Gross, where had the theory of gravitation been, or what would have been achieved in any branch of knowledge requiring more than superficial observation? In answer to the last sentence of the above extract, we would quote the remarks of an excellent Scotch writer-"God denies nothing to well directed diligence." Certainly it is wonderful how much is given to clearheaded and honest labour.

We have no wish to enter into a controversy with the author upon all the points upon which we happen to differ from him, but we cannot pass over two of our author's propositions-the first of which he himself thinks may "be startling" to some; to us we confess both are. The first proposition affirms that, with few exceptions, "all organic diseases, whatever be their seat or extent, are the result of inflammatory action, either of an acute or chronic kind." The second proposition is, "that every inflammation, irritation, or morbid action, is originally of a local nature-that is, it always makes its impression in the first instance upon some particular part, texture, or organ. 
After the malady has continued for a longer or shorter time, it may extend to and implicate other structures." The term organic in the first proposition is made to have a wide latitude, including "every temporary alteration which the tissues experience when in a state of disease." It does startle us that Dr. Gross should pronounce all the minor atrophic changes, the results of debility, anæmia, \&c., fevers ; the great family of scrofulous affections, the manifold degenerations, the whole class of growths, innocent and malignant, to constitute but a few exceptions to his first dogma. No doubt inflammation has a great deal to answer for, but we think decay and morbid growth have quite as much. Of inflammation we may presently say more in particular; but we wish to remark at present, that while we are debating as to the part which it plays in morbid change, we ought to form some tolerably exact idea as to what is to be called inflammation, and to which states the term is to be restricted. Our own view is that the typical case of inflammation, acute or chronic, is easy enough to recognise and decide upon, but that the inflammatory character gradually shades off, and is lost as we advance in the directions of morbid growth and degeneration. The acumen of the pathologist is exercised in determining to which of two types a given case comes nearest, what morbid element is most marked in it. Thus, we suppose fatty liver, fatty heart, arterial atheroma, pulmonary emphysema, anæmia, are organic changes which no one would put down to inflammation; they are typical instances of decay, of failure of the vital power of the several living structures. So, too, we suppose no one" would affirm that a scirrhous, or encephaloid, or fatty tumour, was the result of inflammation; the prominent feature in these is unquestionably that of morbid growth. But with regard to cirrhosis of the liver and granular disease of the kidney, there may be some room for doubt. To our mind, the first comes much nearer to morbid growth than to inflammatory action, and the second to degeneration. But in both there may be a certain dose of inflammatory nisus. The recollection of this caution to denominate any given instance according to the type of morbid action which it most approximates to, will prevent us falling into such errors as those of Broussais' followers, towards which we fear Dr. Gross has a decided leaning.

With regard to the second proposition, we demur quite as much as we do to the first. Does Dr. Gross mean to affirm that small-pox, scarlet-fever, influenza, gout, and rheumatism, are primarily local, and subsequently "extend their sphere of action so as to become general?" No doubt many diseases do proceed in this way, but of a surety quite as many do the reverse. At p. 40 the author reiterates strongly this dogma, and tells us point blank that "if this opinion shall ever be proved to be true, the whole class of febrile maladies, with its hundred varieties and subdivisions, will cease to have a place in our medical treatises." For this day we suspect, however, we shall have long to wait, and meanwhile Dr. Gross's teaching appears to us grievously unsound.

* When writing this we had not perused the section on scirrhus. 
After these introductory statements we come to the subject of inflammation, and all its various attendant conditions or consequences, which are discussed in thirteen chapters. Having expressed his contempt for theories of inflammation (which, however, he takes some notice of at pp. 56-58), Dr. Gross begins with the phenomena. Taking the four Celsian marks as the usually accepted signs of inflammation, he observes that these

"Are not always present, nor are they the only circumstances which occur in inflammation in this disease $(s i c)$ : in every case there is a perversion of the vital actions, attended with an altered state of the nutritive and secretory functions."

\section{Again,}

"If we regard the four phenomena-discoloration, heat, pain, and swelling as being essential to the process, it will be at once perceived that there can be but few inflammations; and we shall therefore be obliged, in describing diseases, to invoke other names, as irritation and fever, a blind adherence to which has unfortunately tended too much to retard the progress of pathological science."

These terms he would have "entirely discarded," and have "diseases named according to the tissues they implicate." It would seem from the above that an alteration or perversion of nutrition and secretion essentially constitutes, in Dr. Gross's eyes, inflammation, and the other ordinarily observed conditions are not necessary. On such a view it is difficult to say what is not inflammation. Yet, while thus advocating the supreme importance of the derangement of nutrition, he speaks at p. 57 slightingly of Dr. Hughes Bennett's theory, which ascribes the production of the redness, heat, pain, and swelling to abnormal nutrition, or in other words, recognises the deranged tissue-force as the chief agent in producing the visible phenomena. To our mind Dr. Gross's view is utterly vague and pointless ; Dr. Bennett's is rational and appropriate to the facts. The former makes no distinction between the typical case and the numerous instances in which the characters are feebly marked, or are in various degrees replaced by others. In objecting to the term irritation, Dr. Gross denies that Mr. Travers or other writers have pointed out "anything concerning the essential character of the disease," or, "told us anything of the peculiar condition of the nervous and vascular systems which accompanies it," Prostration with excitement is the descriptive term used by $\mathrm{Mr}$. Travers to express the characters of irritation, and we think it is undeniably correct. Indeed, we should have thought it quite sufficient to stand by the bedside of a case of delirium tremens, or delirium traumaticum, to satisfy oneself of this. One might, we think, without extraordinary difficulty, perceive that there was high exhausting excitement of the nervous, and prostration or enfeeblement of the circulating, system. The action of remedies, to say nothing of post-mortem examination, would convince most persons, we suppose, that in such cases at least inflammation was out of the question; and that amid all the show of increased activity in the nervous and vascular systems, there was profound debility and failure of functional power. The demonstrated effects of paralysis of the sympathetic upon the arteries does not appear 
to be known to Dr. Gross, nor the almost equally certain influence of the medulla oblongata, and probably other nervous centres, upon the action of the heart. The humid contractions of the latter organ in a weakly person are anything but a sign of increased functional energy, but on the contrary are certainly indicative of debility. Hyperæsthesia, or increased excitability, is almost the sure concomitant of weakness, whatever be the part whose power is failing. An example which we think our author would do well to consider, because it is so free from any local complication, is that of feverish disorder occurring in consequence of over-exertion. A physician of our acquaintance has, on more than one occasion, after prolonged pedestrian exercise, had attacks of this kind, which were once regarded by those who saw him as the commencement of a typhoid fever. We have ourselves observed the same. Here the only pathological change which we can speak certainly of is exhaustion of nervous force. In ordinary cases this is confined to the cerebro-spinal nerves and centres, but in some few it involves the sympathetic, and then the phenomena of pyrexia, or fever, show themselves. As the nervous power is restored by rest, the pyrexial condition ceases. If Dr. Gross assumes a latent inflammation in such cases, have we not a right to say " de non existentibus et de non apparentibus eadem est ratio?" We would fain persuade him to study carefully Virchow's admirable chapter on "Fieber," in the "Handbuch der Speciellen Pathologie und Therapie,' and then to consider whether the phenomena of febrile diseases are not much more intelligible on such a view than on his own.

At p. 45 , remarking on the absence of the ordinary signs of inflammation, heat, pain, \&c., Dr. Gross says:

"In gastritis, the only manifestation of which is frequently irritability without heat, or pain, or uneasiness, or pressure, the digestive function is entirely suspended, gastric juice is no longer secreted, and the organ is oppressed by the mildest articles of food."

This passage gives us a considerable notion of what sort a good many of Dr. Gross's inflammations are. In England we should look on such symptoms as simply indicative of debility of the organ, or of disordered sensibility.

At pp. 49 et seq., we have an attempt to analyse the inflammatory process. The author says:

"The very first step in the process of inflammation is an altered sensibility of the part, produced by some hurtful agent, which the system makes an effort to dislodge. To effect this, the local impression is reflected upon the cerebrospinal axis, and through this again upon the heart, which, being sympathetically incited to increased action, sends more blood to the part concerned than it is accustomed to receive, at the same time that the capillaries are perceptibly dilated. ..... That these vessels do contract and dilate no one will dispute, for experiment has fully decided this point."

We must remark on this passage, 1st, That the system making an effort to dislodge a cause of irritation, is quite a myth, a teleological fancy, which should not be introduced in a "science of observation and induction;" 2, That it puzzles us to conceive how the heart is to 
send more blood to one part than to another, to cause "preternatural determination of blood," in consequence of having its action accelerated; 3, That Bidder has shown that the capillaries possess no contractility, and do not contract and dilate, a point of which our own observations have quite convinced us ; 4, That everybody, we believe, is agreed that the arteries are the regulators of the blood-current, allowing more or less afflux to a given part to take place.

The subject of congestion and discoloration is well treated, and there are some good remarks at p. 56 of the deceptive resemblances between these states and inflammatory redness. The so-called terminations of inflammation are correctly stated to be for the most part concomitant conditions of the process. Chapter II., respecting the effusion of semen, contains nothing of novelty, except a notable instance of our author's highly inflammatory diathesis. He argues that, because inflammatory congestion may have quite disappeared when copious serous effusion has taken place, therefore our ordinary dropsies, such as occur with obstructed portal vein, or cardiac alveolar alterations, are dependent on inflammation, and not simply on the mechanical obstruction. The passage (see pp. 62,63) is too long to quote. We can only give our readers the conclusion, which Dr. Gross thinks is obvious, but which neither his facts nor his reasoning appear to our mind in the least to warrant: "The effusion of serosity, no matter in what part, organ, or region it occurs, is invariably the result of a process analogous to, if not strictly identical with, inflammation." We may remark incidentally, that it seems to us objectionable to alter, even by translation, familiar terms, and we really do not see what advantage is gained by calling the inferior vena cava, "the ascending hollow vein." A novice might imagine that all veins were not hollow.

Chapter III. describes Lymphization-a term meant to be parallel with suppuration, and which we are content to accept. The information given on this subject is fairly complete, and in particular the question of the vascularization of effused fibrin is well treated. After describing the outgrowth process, Dr. Gross affirms his belief in at least the possibility of the independent development of vessels. He says:

"In the pleura it has often occurred to me to see as many as three, four, five, and even six, layers of this substance (exuded lymph) arranged so as to intercept cavities of various sizes, filled with serum, plates of fibrin, pus, and even blood. In some of the cases the circumstances were such as to render it perfectly certain that the development of these adventitious membranes must have taken place with so much rapidity as to preclude the idea that their vascularization could be effected through the agency of the subjacent serous structure."

$\mathrm{Mr}$. Paget's testimony is very strong in favour of the outgrowth view, and Mr. Simon's is also on the same side. Rokitansky, in the second edition of his first volume (on General Pathology), seems to have changed his views so as to incline much more to the outgrowth theory than he did in the first edition. Our own examinations incline us to agree with Dr. Gross and others; the notes of one we subjoin. 
A healthy man died with double pneumonia; the surface of the right pleura was coated throughout with a thin layer of recent lymph, which formed here and there thickish yellow patches; many of these contained distinct red spots, none larger than a pin's head and some smaller. Close scrutiny of these spots showed positively that they were formed of circumscribed masses of blood-globules, lying imprisoned in a firm fibroid and partly corpuscular substance, which contained also much diffused oily matter. The blood-globules appeared normal; there were no pigment grains around them. Nothing was to be seen of any development of vessels, but vacuolæ had begun to form in the fibrinous substance. The blood-spots were principally situated on the attached surface of the exudation layer, but at various depths; they were all actually in the substance of this, and not on its surface. The development of new blood in exudation-blastema, if established, would be an important point with reference to the hypothesis maintained by some as to the part taken by the ductless and lymphatic glands in the formation of blood. It would show that blood might be produced independently of their influence.

Chapter IV., on Suppuration, we can cordially recommend as containing a large amount of good information, more than, perhaps, is to be met with in any other work. Dr. Gross affirms, perhaps correctly, that

"In what is called a cold abscess, the formation of which is sometimes the work of months, inflammation is just as much concerned as in a phlegmonous boil that is developed in two or three days. The only difference is, that in the one the process goes on slowly, almost imperceptibly, while in the other it proceeds rapidly."

The pus of these abscesses, he says, is essentially scrofulous, of thin whey-like consistence, intermixed with small caseous flakes. Mr. Paget gives a very similar account, but intimates that the pus has undergone degeneration. It seems to us open to question whether, in these abscès froids, the process is not one of slow effusion of fibrinous fluid, which corpusculates into puriform matter, and is more like to deposition of tubercle, or of bacony matter, than to the actions of inflammation. Certainly, hyperæmic afflux does not seem necessary.

In the chapter on Hæmorrhage it is assumed that blood-globules may escape through the same pores as give passage to fluids and gases, and thus hæmorrhage by exhalation is explained. This opinion, we suspect, will satisfy the minds of none who have ever looked at a capillary through the microscope. In the case referred to, we see no other possibility than that the consistence of the homogeneous membrane becomes changed, softened, gelatinous, so as to be easily penetrated. After a short chapter on Softening we come to Gangrene, which is treated of pretty fully. True to his hobby, Dr. Gross can form no other idea of the mode of action of ergot in producing gangrene, except that "it exerts its deleterious impression in the first instance upon the blood, and through it upon the capillaries, causing inflammation in them, followed by gangrene." The opinion first put forth by Mr. Simon, that the action of ergot in causing gangrene is of the same 44-xxIr. 
kind as in causing uterine contraction, in both instances stimulating organic muscular fibre to contract, is to our mind a great deal more probable than that of the author. M. Trousseau, noticing the occasional occurrence of sphacelus in those peasants who use ergotized rye as food, says, "Sphacèle qui suivant toutes les apparences est causé par l'obliteration des vaisseaux artériels de la partie." The account given by Dr. Gross would lead us to believe that the epidemic prevalence of gangrene in various parts of Europe at different times was owing to the use of ergot. This view is entirely rejected by Trousseau, and apparently on sufficient evidence. Ulceration is, of course, in $\mathrm{Dr}$. Gross's mind, essentially connected with inflammation, and we shall not think it worth while to argue the reverse; only we hope that if we ever have simple ulceration of the cornea, we shall not fall into the hands of one of his disciples.

Granulations the author regards as of "extremely complex structure." It rather appears to us they are of extremely simple structure, consisting solely of nascent or embryonic areolar tissue and bloodvesselss with an epithelial investment.

The chapters on Cicatrization, Induration, Hypertrophy, and Atrophy, call for no particular remark.

Transformations are well described, and judicious intimations given that the change produced is often more of an incomplete than perfect. kind. Dr. Gross is " disposed to think" that fatty transformation is "uniformly the result of a low and imperceptible grade of inflammatory irritation." We are quite disposed to agree with him as to its being imperceptible!

The account of Pneumatoses in Chapter XVI. is very full and interesting-more so than any other we know.

Chapter XVII. is devoted to a description of Polypes, and though there is not much to find fault with in it, but rather the reverse, we must take exception to the heading. Dr. Gross allows that it is not very appropriate, but thinks it would only occasion confusion to change it. The name might have been retained for occasional use if he had grouped the tumours to which it is applied under the head of fibrocellular, as Mr. Paget has done, or tegumentary, after the example of Mr. Simon. That these growths are "liable to take on malignant disease," is a statement which few pathologists of the present day will be inclined to assent to. Dr. Gross seems to consider it no uncommon occurrence.

Chapter XVIII. gives a pretty full and exact account of hydatids. We feel surprised, however, to read that the proper hydatid membrane is exceedingly delicate, so as to yield under the slightest pressure of the finger. Its curly tendency and peculiar lamination are not at all noticed.

Chapter XIX., on Serous Cysts, treats of all the various kinds of these formations. The distinctive epithet would have been better omitted.

Chapter XX. treats of Heterologous Formations, intending thereby tubercle, melanosis, scirrhus, encephaloid, colloid, epithelial cancer. 
We quite join the author in his suspicion that the term heterologons is "altogether ill-chosen and out of place," and we think it would have been much better if he had forborne from any such grouping. The subject of tubercle is discussed in about sixteen pages, which of course are mainly a compilation from the works of others. The only points which seem to require notice, and that we are sorry to say in the way of protest, are the statements "that tubercles are organized structures," and that they are "always of inflammatory origin," though of a very mild and imperceptible kind. As to the latter point, we can scarcely imagine any feebler array of arguments than those six set down at pp. 157,158 , which we shall not take up space to reproduce in full. Ex uno disce omnes. "In the experiments of Cruveilhier, Kay, and Saunders, well-characterized tubercles were produced in a very short time, simply by dropping mercury into the trachea." M. Andral, repeating these experiments, found, as might have been expected, that the metallic globules had simply become surrounded by purulent matter or false membrane. After this we have the case of the needlegrinders, miners, \&c., who inhale irritating matters, cited, and it is stated that they are peculiarly prone to phthisis. The evidence adduced by $\mathrm{Mr}$. Ancell from various sources makes it almost certain, however, that tubercles are not produced in these workers without the intervention of other causes.

As to the question of organization, Dr. Gross does not assert that tubercles are invariably organized-e.g., where the tuberculous matter is spread over the free surface of mucous membranes. In other situations, however, he is satisfied that they possess vessels of their own, and even thinks it quite philosophical to infer the existence of nerves and absorbents. "If under favourable circumstances plastic lymph is capable of generating its own vessels, why should not tubercle be? Because, Dr. Gross, tubercle is eminently $a$-plastic.

The section on Melanosis contains a tolerably full résumé of the facts known respecting it. The author seems to be satisfied that it is a separate and distinct affection, and not merely an accident which may attach to various growths. This idea causes him to consider it very remarkable that in a case of widely disseminated melanotic cancer which he met with, there existed numerous white and greyish tubercles in the midst of the black. To our mind there is nothing remarkable in it.

We proceed to Scirrhus, respecting which our author concludes,-

"First, that the deposit of scirrhus is preceded by inflammation; secondly, that it has a great predilection for the glandular viscera; thirdly, that it rarely occurs under the age of forty; fourthly, that the matter of which it consists, when first deposited, strongly resembles that of tubercle; and lastly, that this matter is deposited always into the cellular tissue of our organs, in such a manner as to transform their proper parenchymatous structure."

Not one of these conclusions can we consider free from objection. The third, which is nearest the truth, ought to have been modified by a reference to Mr. Paget's table, showing that in 98 cases out of 400 , or nearly 1 in 4 , the cancer was observed before the completion of the 
fortieth year. The expression "transform," used in the last, is objectionable, though from the context we believe Dr. Gross to mean that the new growth causes wasting of the adjacent parts.

The sections on Encephaloid, Colloid, and Epithelial Cancer are not to be regarded as very complete, or as fairly representing the present state of our knowledge; still, they contain a good deal of what is most certain, and we do not observe any statement that we are disposed to quarrel with.

We have thus taken a cursory review of the first part of this volume, and regret that want of space precludes us from entering on the second, which is devoted to special pathological anatomy. We feel, however, bound to say, after looking through it carefully, that we are quite satisfied of its possessing great merit. It is full of descriptive detail, based evidently in great part on original observation, and abundantly illustrated by very excellent woodcuts. There is not much of minute investigation of diseased structure, but all the grosser and more manifest changes are very completely described. The work is quite a repertory of fact, and will almost bear a comparison with that of Rokitansky in this respect. The author evidently belongs to the older generation of pathologists, to those who loved to create a museum round them, and to whom a "beautiful specimen" was of more value than the development of a principle or the explanation of a morbid process. The work of these men is good and sound, though not of the highest order : it is rather preliminary than final.

Dr. Peaslee's compilation has for its aim:

" 1 . To give a connected view of the simple chemical elements, of the immediate principles, the simple structural elements, and the proper tissues entering into the composition of the fluids and the solids of the human body. 2. To associate with the structural elements and the tissues their function while in health, and the changes they undergo in disease."

In fulfilling his purpose, the author has laid under contribution most of the best works on the subjects he has to deal with, and he gives a list of these sources of information at the end of his volume. Woodcuts and engravings have been borrowed even more freely than the text, and we hardly think with sufficient acknowledgment. A great amount of information no doubt has been brought together, and a book manufactured which may certainly be useful to the student. We should, however, be glad to see American professors more given to producing, and American students more given to reading, original works.

The title of Dr. Valentin's little work involuntarily reminds us of a hospital patient who one day urgently requested us to give him some medicine "to remove his bowels!" We hope our readers and the author will pardon this descent from critical gravity, and we proceed to say what we think of the leitfaden presented to us. It is a systematic detail of the best methods of conducting post-mortem examinations, and may be perused, we donbt not, with much benefit by any who have had no great experience in that way, and have no careful prosector to guide them. We cannot but think, however, that 
half-a-dozen practical lessons by Dr. Valentin or his compeers would convey very much more usable instruction than the perusal of the pamphlet. As somewhat old and cunning in this matter ourselves, we will venture one or two remarks. In removing the brain, Dr. Valentin directs to divide the tentorium along the edge of the petrous bone, but to leave it attached to the groove of the horizontal sinus. We prefer to divide it right round at once, so as to bring it away with the encephalic mass, because otherwise it holds the latter after it is turned out of the cranial cavity. Dr. Valentin does not notice the special difficulty which meets us in examining the heads of young children, where the dura mater cleaves so fast to the thin and weak bones, that it is next to impossible to separate it from them. In this case we adopt the proceeding of cutting through the dura mater after sawing through the skull, and then, without attempting to remove the upper segment, dividing the falx cerebri, and raising up the brain and turning it out into the still adherent skull-cap. With the aid of an assistant to divide the tentorium, this may be done very nicely. Our author insists that the hypophysis should be removed still attached to the infundibulum. We can scarcely conceive the possibility of doing this - at least, in the majority of cases - on account of the delicacy of the connexion, and we cannot see the advantage of it, unless the object were to make a perfect anatomical preparation.

\section{Review III.}

1. A Theoretical and Practical Treatise on Midwifery, including the Diseases of Pregnancy and Parturition, and the Attentions required by the Child from Birth to the Period of Weaning. By P. Cazeaux, Member of the Imperial Academy of Medicine, Adjunct Professor in the Faculty of Medicine of Paris, \&c. \&c. Second American (translated from the fifth French) Edition. By WM. R. Bullock, M.D. With 140 Illustrations.-Philadelphia, 1857. 8vo, pp. 992.

2. The Principles and Practice of Obstetrics; including the Treatment of Chronic Inflammation of the Uterus, considered as a frequent Cause of Abortion. By Henry Miller, M.D., Professor of Obstetric Medicine in the Medical Department of the University of Louisville. With Illustrations on Wood.-Philadelphia, 1858. Svo, pp. 624.

3. Elements of Practical Midwifery; or, Companion to the Lying-in Room. By Charles Waller, M.D., Obstetric Physician to, and Lecturer on Midwifery at, St. Thomas's Hospital. Fourth Edition,with Plates.-London, 1858. 12mo, pp. 193.

The above treatises, of respectively French, American, and English origin, although differing widely in their scope and character, reflect some of the more striking peculiarities of the national literature to which they severally belong. Thus, the French work is distinguished 